UDC $517.927 .4: 519.624 .2$

DOI: $10.20535 /$ SRIT.2308-8893.2021.4.09

\title{
APPLICATION OF TWO-SIDED APPROXIMATIONS METHOD TO SOLUTION OF FIRST BOUNDARY VALUE PROBLEM FOR ONE-DIMENSIONAL NONLINEAR HEAT CONDUCTIVITY EQUATION
}

\author{
N. GYBKINA, M. SIDOROV, K. VASYLYSHYN
}

\begin{abstract}
The first boundary value problem for a one-dimensional nonlinear heat equation is considered, where the heat conductivity coefficient and the power function of heat sources have a power-law dependence on temperature. For a numerical analysis of this problem, it is proposed to use the method of two-sided approximations based on the method of Green's functions. After replacing the unknown function, the boundary value problem is reduced to the Hammerstein integral equation, which is considered as a nonlinear operator equation in a semi-ordered Banach space. The conditions for the existence of a single positive solution of the problem and the conditions for two-sided convergence of successive approximations to it are obtained. The developed method is programmatically implemented and researched in solving test problems. The results of the computational experiment are illustrated by graphical and tabular information. The conducted experiments confirmed the efficiency and effectiveness of the developed method that allowed recommending its practical use for solving problems of system analysis and mathematical modeling of nonlinear processes.
\end{abstract}

Keywords: nonlinear thermal conductivity, positive solution, Green's function, twosided iterative method, equation with isotonic operator.

\section{INTRODUCTION}

System studies of various objects and processes require the use of the method of mathematical modeling and the apparatus of computational mathematics. In particular, the problem of mathematical modeling of nonlinear stationary heat conduction processes leads to the need of developing the effective numerical methods for solving initial, boundary value and initial boundary value problems for quasilinear differential equations with a coefficient nonlinearly dependent on temperature [1-4]. Today there are many methods of numerical analysis of these problems. Among them are methods of similarity theory, methods of finite differences, finite elements, boundary integral equations $[1,5-8]$ or successive approximations with two-sided convergence $[9,10]$. The methods of the last group allow to build two sequences of functions, which, respectively, from the bottom and top approach the desired solution of the problem. Due to this fact, in the implementation of these methods, we have a convenient a posteriori estimation of the approximations error, and hence a convenient criterion for the end of iterations. This makes the methods of two-sided approximations more attractive than other methods used to solve boundary value problems for stationary equations.

The purpose of the work is to develop on the base of the Green's function method the method of two-sided approximations for solving the first boundary 
value problem for a nonlinear one-dimensional equation of thermal conductivity and to study its work in solving test problems.

The construction of two-sided approximations methods for solving boundary value problems for partial differential equations is based on the use of the theory of nonlinear operators in semi-ordered spaces. The theory of linear semi-ordered spaces was built by L.V. Kantorovich in the second half of the 30's XX century [11]. Further development of the methods of this theory is associated with the work of M.A. Krasnoselsky [12], H. Amann [13], V.I. Opoytsev [14], N.S. Kurpel, B.A. Shuvar [15], A.I. Kolosov [16]. In [12] the question of the existence of positive solutions of equations with monotone operators was investigated, and in [14] the solvability of equations with operators that have a generalized property of monotonicity (so-called heterotonic or mixed monotone operators) was investigated. These works laid the theoretical foundations for the development of twosided iterative schemes, but the iterations themselves were considered by the authors as an aid to prove the theorems of the existence of fixed points of operators and did not lead to computational results.

Works $[9,10]$ are devoted to the development of two-sided iterative schemes for solving boundary value problems for partial differential equations as means of applied mathematics with bringing them to computational implementation. In this case, only the first boundary value problem for a semilinear elliptic equation with the Laplace operator and power or exponential nonlinearity was mainly considered.

This work continues the research started in $[9,10]$ and aims to generalize them and extend them to ordinary nonlinear differential equations.

So, we will consider the problem of finding a solution to a nonlinear boundary value problem, which is a mathematical model of thermal conductivity in a rod of length $l$, when the thermal conductivity coefficient has a power-law dependence on temperature and when there are heat sources in the rod distributed according to the power law:

$$
\begin{gathered}
-\frac{d}{d x}\left(k(T) \frac{d T}{d x}\right)=\lambda f(T), 0<x<l, \\
T(x)>0,0<x<l, \\
T(0)=T(l)=0,
\end{gathered}
$$

where $k(T)=k_{0} T^{\sigma}$ is heat conductivity coefficient, $k_{0}>0$ is the value of the thermal conductivity in a linear medium, $f(T)=T^{\gamma}$ is heat source power function, $\sigma>0, \gamma>0$ are parameters of nonlinearity of the medium, $\lambda>0$ is constant, which characterizes the power of heat sources.

To analyze the boundary value problem (1) - (3), we apply the methods of the theory of nonlinear operators in semi-ordered spaces [12, 14].

\section{MATERIALS AND METHODS}

Let us present some definitions and facts from the theory of nonlinear operators in semi-ordered spaces, which will be used below $[12,14]$.

Let $\mathcal{U}$ be a real Banach space, and $\theta$ be a zero element of the space $\mathcal{U}$. A cone is a closed convex set $\mathcal{K} \subset \mathcal{U}$ for which the following conditions hold:

a) if $u \in \mathcal{K}$ and $u \neq \theta$, then $\gamma u \in \mathcal{K}$ for any $\gamma \geq 0$;

b) if $u \in \mathcal{K}$ and $u \neq \theta$, then $-u \notin \mathcal{K}$. 
An arbitrary cone $\mathcal{K} \subset \mathcal{U}$ allows one to introduce semi-ordering in the space $\mathcal{U}$ according to the rule: $v \leqslant w$, if $w-v \in \mathcal{K}$. Elements $u \geqslant \theta$ (i.e., $u \in \mathcal{K}$ ) are called positive. The set of elements $\langle v, w\rangle$ of a semi-ordered space, which consists of those $u \in \mathcal{U}$ for which $v \leqslant u \leqslant w$, is called a conical segment.

Normal cones are an important class of cones for applications of the theory of semi-ordered spaces in computational mathematics. A cone $\mathcal{K}$ is called normal if there exists a number $N(\mathcal{K})>0$ such that $\|v\| \leq N(\mathcal{K})\|w\|$ follows from $\theta \leqslant v \leqslant w$. In this case, one says that the norm is semi-monotonous. If $N(\mathcal{K})=1$, then the cone is called acute, and it is said that the norm is monotonic.

Let us present the definition of some classes of operators in spaces with a cone.

An operator $T: \mathcal{U} \rightarrow \mathcal{U}$ is said to be positive if it leaves an invariant cone $\mathcal{K}$, i.e., $T(u) \in \mathcal{K}$ for any $u \in \mathcal{K}$.

Let some non-zero element $u_{0} \in \mathcal{K}$ be fixed. Denote by $K\left(u_{0}\right)$ the set of those elements $u \in \mathcal{K}$ for which we can specify such $\alpha=\alpha(u)>0, \beta=\beta(u)>0$ that $\alpha u_{0} \leqslant u \leqslant \beta u_{0}$.

An important subclass of positive operators is the so-called $u_{0}$-positive operators. A positive operator $T$, which translates the nonzero elements of the cone $\mathcal{K}$ into $K\left(u_{0}\right)$, is called an $u_{0}$-positive operator. Therefore, for an $u_{0}$-positive operator $T$ for any $u \in \mathcal{K}, u \neq \theta$ there are such $\alpha=\alpha(u)>0, \beta=\beta(u)>0$ that $\alpha u_{0} \leqslant T(u) \leqslant \beta u_{0}$.

The operator $T: \mathcal{U} \rightarrow \mathcal{U}$, which acts in $\mathcal{U}$, is called monotonic (isotonic), if from $u, v \in \mathcal{U}, u \geqslant v$ follows $T(u) \geqslant T(v)$.

An operator $T: \mathcal{U} \rightarrow \mathcal{U}$ is called concave if it is $u_{0}$-positive for any $u \in K\left(u_{0}\right)$ and $\tau \in(0,1)$

$$
T(\tau u) \geqslant \tau T(u)
$$

and in (4) equality is impossible.

A concave operator $T$ is called $u_{0}$-concave if it is $u_{0}$-positive and for any $u \in K\left(u_{0}\right)$ and $\tau \in(0,1)$ there is a $\eta=\eta(u, \tau)>0$ such that

$$
T(\tau u) \geqslant \tau(1+\eta) T(u) \text {. }
$$

Consider the equation

$$
u=T(u)
$$

with a positive nonlinear operator $T: \mathcal{U} \rightarrow \mathcal{U}$, and the Banach space $\mathcal{U}$ is semiordered by a cone $\mathcal{K}$. We are interested in the conditions under which this equation will have at least one nonzero solution $u^{*}$ in the cone $\mathcal{K}$. This solution $u^{*} \geqslant \theta, u^{*} \neq \theta$ is called the positive solution of equation (5). In the case when $T(\theta)=\theta$, we are talking about another, different from $\theta$, solution in the cone $\mathcal{K}$.

Let us first consider the question of the existence of a fixed point in an isotonic operator.

A conical segment $<v_{0}, w_{0}>$ is said to be invariant for the isotonic operator $T$ if the inequalities hold

$$
T\left(v_{0}\right) \geqslant v_{0}, \quad T\left(w_{0}\right) \leqslant w_{0} .
$$


Therefore, the invariance of the conical segment $\left\langle v_{0}, w_{0}\right\rangle$ means that $T\left(<v_{0}, w_{0}>\right) \subset<v_{0}, w_{0}>$.

Let the isotonic operator $T$ have an invariant conic segment $\left\langle v_{0}, w_{0}\right\rangle$. Consider the iterative process

$$
u^{(k+1)}=T\left(u^{(k)}\right), k=0,1,2, \ldots .
$$

The following statement takes place $[12,14]$.

Theorem 1 (about the existence of a fixed point in an isotonic operator). Let the isotonic operator $T$ have an invariant conic segment $\left\langle v_{0}, w_{0}\right\rangle$, the cone $\mathcal{K}$ is normal, and the operator $T$ is completely continuous. Then successive approximations (7) coincide to $v^{*}$ at $u^{(0)}=v_{0}$ and to $w^{*}$ at $u^{(0)}=w_{0}$. Points $v^{*}$ and $w^{*}$ are fixed points of the operator $T$, and if $u^{*} \in<v_{0}, w_{0}>$ is any other fixed point of $T$, then the inequalities $v^{*} \leqslant u^{*} \leqslant w^{*}$ hold. If it is known in advance that the fixed point $u^{*} \in<v_{0}, w_{0}>$ is unique, then the iterative process (7) coincides with $u^{*}$ from any initial point $u^{(0)} \in<v_{0}, w_{0}>$.

So, consider an iterative scheme

$$
\begin{gathered}
v^{(k+1)}=T\left(v^{(k)}\right), w^{(k+1)}=T\left(w^{(k)}\right), k=0,1,2, \ldots, \\
v^{(0)}=v_{0}, w^{(0)}=w_{0} .
\end{gathered}
$$

As we can see, scheme (8) is a set of two independent iterative processes, and therefore, its computational implementation can be performed using parallel calculations.

The condition that guarantees the existence of a single fixed point $u^{*}$ of the isotonic operator $T$ is its $u_{0}$-concavity. Then for the $u_{0}$-concave operator $T$ the iterative process $(8)$ will coincide bilaterally to this fixed point, i.e.

$$
v_{0}=v^{(0)} \leqslant v^{(1)} \leqslant \ldots \leqslant v^{(k)} \leqslant \ldots \leqslant u^{*} \leqslant \ldots \leqslant w^{(k)} \leqslant \ldots \leqslant w^{(1)} \leqslant w^{(0)}=w_{0} .
$$

Thus, the application of the method of two-sided approximations to find a solution to equation $u=T(u)$ with an isotonic operator $T$ is as follows:

1) construct a cone segment $\left\langle v_{0}, w_{0}\right\rangle$ invariant for the isotonic operator $T$ using conditions (6);

2 ) using the $u_{0}$-concavity condition, draw a conclusion about the existence of a unique on $<v_{0}, w_{0}>$ solution $u^{*}$ of equation (5) and two-sided convergence to it of successive approximations (8);

3) set the accuracy $\varepsilon>0$ and, using the iterative scheme (8), construct the sequences $\left\{v^{(k)}\right\},\left\{w^{(k)}\right\}$;

4) if $\left\|w^{(k)}-v^{(k)}\right\|<2 \varepsilon$, then write the approximate solution of equation (5) $u^{(k)}=\frac{v^{(k)}+w^{(k)}}{2}$, in this case $\left\|u^{*}-u^{(k)}\right\|<\varepsilon$, i.e. $u^{*} \approx u^{(k)}$ with accuracy $\varepsilon$. 
TWO-SIDED APPROXIMATIONS METHOD FOR SOLVING

ONE-DIMENSIONAL BOUNDARY VALUE PROBLEMS FOR NONLINEAR

EQUATION OF THERMAL CONDUCTIVITY BASED ON THE USE

OF GREEN FUNCTION

Making the substitution $T=\left[\frac{\sigma+1}{k_{0}} u\right]^{\frac{1}{1+\sigma}}$ in problem (1) - (3), where $u(x)$ is a new unknown function, we obtain for the function $u$ the boundary value problem

$$
\begin{gathered}
-u^{\prime \prime}=\mu F(u), \quad x \in(0, l), \\
u(x)>0, \quad x \in(0, l), \\
u(0)=0, u(l)=0,
\end{gathered}
$$

where $F(u)=u^{\frac{\gamma}{1+\sigma}}, \mu=\lambda\left(\frac{\sigma+1}{k_{0}}\right)^{\frac{\gamma}{1+\sigma}}$.

The function $F(u)$ is continuous and positive for $u>0$.

For problem (9) - (11) the Green's function $G(x, s)$ has the form

$$
G(x, s)= \begin{cases}\frac{x(l-s)}{l}, & 0 \leq x \leq s, \\ \frac{s(l-x)}{l}, & s \leq x \leq l .\end{cases}
$$

As one can see, $G(x, s) \geq 0$ for all $0 \leq x, s \leq l$. Then the problem (9) - (11) is equivalent to Hammerstein's integral equation

$$
u(x)=\mu \int_{0}^{l} G(x, s) F(u(s)) d s .
$$

Consider the equation (13) in the Banach space $C[0, l]$ of functions continuous on the segment $[0, l]$. The norm in $C[0, l]$ is introduced by a rule $\|u\|=\max _{x \in[0, l]}|u(x)|$. Select in $C[0, l]$ the cone $\mathcal{K}_{+}=\{u \in C[0, l]: u(x) \geq 0, x \in[0, l]\}$ of nonnegative functions. Cone $\mathcal{K}_{+}$in $C[0, l]$ is normal (and even acute) [12]. In the space $C[0, l]$, using the cone $\mathcal{K}_{+}$, one can introduce semi-ordering using the rule:

$$
\text { for } u, v \in C[0, l] u \leqslant v \text {, if } v-u \in \mathcal{K}_{+} \text {, }
$$

i.e.

$$
u \leqslant v, \text { if } u(x) \leq v(x) \text { for all } x \in[0, l] .
$$

If there is a classical solution to problem (9) - (11), that is, a function $u^{*} \in C^{2}(0, l) \cap C[0, l]$ satisfying the conditions (10), (11) and equation (9), then we can conclude that this function also satisfies the integral equation (13). If the classical solution is absent, then the definition of the generalized solution of problem (9) - (11) can be based on the integral equation (13). Namely, we can intro- 
duce the definition of the solution (generalized) of the boundary value problem (9)-(11) as a function $u^{*} \in \mathcal{K}_{+}$, which is the solution to the integral equation (13).

Connect the equation (13) with the nonlinear integral operator $T$ acting in $C[0, l]$ by the rule

$$
T(u)(x)=\mu \int_{0}^{l} G(x, s) F(u(s)) d s .
$$

Let us investigate some properties of the operator $T$ of the form (14).

Firstly, the operator $T$ of the form (14) is positive, i.e., it leaves cone $\mathcal{K}_{+}$an invariant: $T\left(\mathcal{K}_{+}\right) \subset \mathcal{K}_{+}$. Indeed, the Green's function is continuous and nonnegative in the square $0 \leq x, s \leq l$. Then, taking into account condition (10) for any $u \in C[0, l]$, the integrand in (14) is continuous and nonnegative at $0 \leq x, s \leq l$, and therefore, the function $T(u)(x)$ is continuous and nonnegative on the interval $[0, l]$, that is, from $u \in \mathcal{K}_{+}$it follows that $T(u) \in \mathcal{K}_{+}$.

Secondly, the operator $T$ of the form (14) is an $u_{0}$-positive operator with

$$
u_{0}(x)=\int_{0}^{l} G(x, s) d s=\frac{1}{2} x(l-x),
$$

because for the Green's function of the form (12) there is an estimate

$$
\varphi(s) u_{0}(x) \leq G(x, s) \leq \psi(s) u_{0}(x), 0 \leq x, s \leq l,
$$

where $\varphi(s)=\frac{2}{l^{2}} \min \{s, l-s\}, \psi(s)=\frac{2}{l}$.

Then, if $u \in \mathcal{K}_{+}, u \neq \theta$, then there is an inequality

$$
\alpha u_{0}(x) \leq \mu \int_{0}^{l} G(x, s) F(u(s)) d s \leq \beta u_{0}(x),
$$

where $\alpha=\mu \int_{0}^{l} \varphi(s) F(u(s)) d s>0, \beta=\mu \int_{0}^{l} \psi(s) F(u(s)) d s$.

So, if $u \in \mathcal{K}_{+}, u \neq \theta$, then $T(u) \in K\left(u_{0}\right)$, that is, $T(u) \in \mathcal{K}_{+}$, and there are such $\alpha=\alpha(u)>0, \beta=\beta(u)>0$, that $\alpha u_{0} \leqslant T(u) \leqslant \beta u_{0}$.

Since $\sigma>0, \gamma>0$, the function $F(u)$ grows monotonically by $u$, from which it follows that the operator $T(u)$ of the form (14) will be isotonic.

Obviously, the operator $T$ is completely continuous.

Find the conditions under which the isotonic operator $T$ of the form (14) will be $u_{0}$-concave with the function $u_{0}(x)$ of the form (15). As it is known [12], the definition of $u_{0}$-concavity will be fulfilled under the condition: for any positive number $u$ for any $\tau \in(0,1)$

$$
F(\tau u)>\tau F(u) .
$$

For the function $F(u)=u^{\frac{\gamma}{1+\sigma}}$ the condition (17) takes the form

$$
(\tau u)^{\frac{\gamma}{1+\sigma}}>\tau \cdot u^{\frac{\gamma}{1+\sigma}}
$$


wherefrom

$$
\tau^{\frac{\gamma}{1+\sigma}-1}>1
$$

that is,

$$
\gamma<1+\sigma .
$$

Therefore, if condition (18) is satisfied, the operator $T$ of the form (14) will be $u_{0}$-concave.

Thus, the following statement is held.

Lemma 1. The operator $T$ of the form (14), where $G(x, s)$ is the Green's function (12) of the problem (9) - (11), which acts in the space $C[0, l]$, semiordered by the cone $\mathcal{K}_{+}$of nonnegative functions, has the following properties:

a) it is a positive operator;

b) it is an $u_{0}$-positive operator, where the function $u_{0}(x)$ is defined by equality (15);

c) it is an isotonic operator;

d) if inequality (18) holds, it is an $u_{0}$-concave operator, where function $u_{0}(x)$ has the form (15).

In cone $\mathcal{K}_{+}$we distinguish the invariant conical segment $\left\langle v_{0}, w_{0}\right\rangle$ by conditions (6), which for the operator $T$, determined by equation (14), take the form

$$
\begin{aligned}
& \mu \int_{0}^{l} G(x, s) F\left(v_{0}(s)\right) d s \geq v_{0}(x) \text { for all } x \in[0, l], \\
& \mu \int_{0}^{l} G(x, s) F\left(w_{0}(s)\right) d s \leq w_{0}(x) \text { for all } x \in[0, l] .
\end{aligned}
$$

Let us form an iterative process according to the scheme:

$$
\begin{gathered}
v^{(k+1)}(x)=\mu \int_{0}^{l} G(x, s) F\left(v^{(k)}(s)\right) d s, k=0,1,2, \ldots, \\
w^{(k+1)}(x)=\mu \int_{0}^{l} G(x, s) F\left(w^{(k)}(s)\right) d s, k=0,1,2, \ldots, \\
v^{(0)}(x)=v_{0}(x), w^{(0)}(x)=w_{0}(x) .
\end{gathered}
$$

Taking into account the invariance of the cone segment $\left\langle v_{0}, w_{0}\right\rangle$ and the isotonicity of the operator $T$, we can conclude that the sequence $\left\{v^{(k)}(x)\right\}$ does not decrease along the cone $\mathcal{K}_{+}$, and the sequence $\left\{w^{(k)}(x)\right\}$ does not increase along the cone $\mathcal{K}_{+}$. In addition, from the normality of the cone $\mathcal{K}_{+}$and the complete continuity of the operator $T$ follows the existence of the boundaries $v^{*}(x)$ and $w^{*}(x)$ of these sequences. Thus, the chain of inequalities is true

$$
v_{0}=v^{(0)} \leqslant v^{(1)} \leqslant \ldots \leqslant v^{(k)} \leqslant \ldots \leqslant v^{*} \leqslant w^{*} \leqslant \ldots \leqslant w^{(k)} \leqslant \ldots \leqslant w^{(1)} \leqslant w^{(0)}=w_{0} .
$$

There are two possible cases: $v^{*}<w^{*}$ and $v^{*}=w^{*}$. If the operator $T$ is $u_{0}$ concave, then only the second case is possible, and then $u^{*}:=v^{*}=w^{*}$ is the only 
fixed point of the operator $T$ on the conical segment $\left\langle v_{0}, w_{0}>\right.$, and hence $u^{*}$ is the unique on $<v_{0}, w_{0}>$ positive solution of the boundary value problem (9)-(11).

Thus, the following theorem holds.

Theorem 2. Let $\left\langle v_{0}, w_{0}\right\rangle$ be an invariant conic segment for an isotonic operator $T$ of the form (14) and condition (18) holds. Then the iterative process $(21)-(23)$ converges according to the norm of the space $C[0, l]$ to the unique on $<v_{0}, w_{0}>$ continuous positive solution $u^{*}$ of the boundary value problem (9) (11), and a chain of inequalities takes place

$$
v_{0}=v^{(0)} \leqslant v^{(1)} \leqslant \ldots \leqslant v^{(k)} \leqslant \ldots \leqslant u^{*} \leqslant \ldots \leqslant w^{(k)} \leqslant \ldots \leqslant w^{(1)} \leqslant w^{(0)}=w_{0} .
$$

For the approximate solution of the boundary value problem (9) - (11) on the $k$ th iteration we take the function

$$
u^{(k)}(x)=\frac{w^{(k)}(x)+v^{(k)}(x)}{2} .
$$

The advantage of the constructed two-sided iterative process is that on each $k$ th iteration we have a convenient a posteriori error estimate for the approximate solution (25):

$$
\left\|u^{*}-u^{(k)}\right\| \leq \frac{1}{2} \max _{x \in[0, l]}\left(w^{(k)}(x)-v^{(k)}(x)\right) .
$$

Therefore, if the accuracy $\varepsilon>0$ is given, then the iterative process should be carried out before the inequality $\max _{x \in[0, l]}\left(w^{(k)}(x)-v^{(k)}(x)\right)<2 \varepsilon$ is fulfilled and with the accuracy $\varepsilon$ we can assume that $u^{*}(x) \approx u^{(k)}(x)$.

Then the function

$$
T^{(k)}(x)=\left[\frac{\sigma+1}{k_{0}} u^{(k)}(x)\right]^{\frac{1}{1+\sigma}}
$$

can be considered an approximate solution to the original problem.

Since there is an inequality (16), which means that $T(u) \in K\left(u_{0}\right)$ for any $u \in \mathcal{K}_{+}, u \neq \theta$, then the ends of the invariant conical segment $<v_{0}, w_{0}>$ can be found in the form $v_{0}(x)=\alpha u_{0}(x), w_{0}(x)=\beta u_{0}(x)$, where $0<\alpha<\beta$, and the function $u_{0}(x)$ is determined by equality (14). Then inequalities (19), (20) take the form

$$
\begin{aligned}
& \mu \int_{0}^{l} G(x, s) F\left(\alpha u_{0}(s)\right) d s \geq \alpha u_{0}(x) \text { for all } x \in[0, l], \\
& \mu \int_{0}^{l} G(x, s) F\left(\beta u_{0}(s)\right) d s \leq \beta u_{0}(x) \text { for all } x \in[0, l] .
\end{aligned}
$$

Inequalities (25), (26) can be reduced to the form

$$
\alpha^{\frac{1+\sigma-\gamma}{1+\sigma}} \leq \mu m, \beta^{\frac{1+\sigma-\gamma}{1+\sigma}} \geq \mu M,
$$


where

$$
\begin{gathered}
m=l^{\frac{2 \gamma+\sigma+1}{\sigma+1}} \frac{2^{-1-\frac{3 \gamma}{1+\sigma}} \sqrt{\pi} \Gamma\left(1+\frac{\gamma}{1+\sigma}\right)}{\Gamma\left(\frac{3}{2}+\frac{\gamma}{1+\sigma}\right)}, \\
M=l^{\frac{2 \gamma+\sigma+1}{\sigma+1}} 2^{3-\frac{\gamma}{1+\sigma}} \mathrm{B}\left(\frac{1}{2}, 2+\frac{\gamma}{1+\sigma}, 1+\frac{\gamma}{1+\sigma}\right) .
\end{gathered}
$$

Here $\Gamma(z)=\int_{0}^{+\infty} t^{z-1} e^{-t} d t$ is Euler's gamma function, $\mathrm{B}(z, a, b)=$ $=\int_{0}^{z} t^{a-1}(1-t)^{b-1} d t$ is Euler's incomplete beta function.

Since the value of $\max _{x \in[0, l]}\left(w_{0}(x)-v_{0}(x)\right)=(\beta-\alpha) \max _{x \in[0, l]} u_{0}(x)$ should be as small as possible for faster convergence of iterations, in the practical implementation of the iterative process (21)-(23) one should take the largest $\alpha$ and the smallest $\beta$, satisfying inequalities (27), i.e.

$$
\alpha=(\mu m)^{\frac{\sigma+1}{\sigma-\gamma+1}}, \beta=(\mu M)^{\frac{\sigma+1}{\sigma-\gamma+1}} .
$$

\section{EXPERIMENT, RESULTS AND DISCUSSIONS}

The computational experiment in problem (1)-(3) was carried out for the values of $l=1, k_{0}=1, \lambda=1$ and $\sigma=2,5$, which corresponds to the case of an experiment with a source of energy from thermonuclear reactions in the study of the thermal conductivity of hydrogen plasma [2]. The condition for the convergence of the proposed method of two-sided approximations for finding a positive solution is the condition $\gamma<1+\sigma=3,5$. Making the substitution $T=\left(\frac{7}{2} u\right)^{2 / 7}$, where $u(x)$ is a new unknown function, for the function $u$ we obtain a boundary value problem of the form (9) - (11).

Consider the case where $\gamma=1,6$ (condition $\gamma<1+\sigma$, obviously, is satisfied). By formulas (29), (30) we find $m$ and $M: m=0,30871, M=0,35218$, and by formulas (31) we obtain that $\alpha=0,32951, \beta=0,42000$. So, provided that $u_{0}(x)$ has the form (15) at $l=1$, the invariant cone segment will have the form $<\alpha u_{0}, \beta u_{0}>$. The iterative process (21) $-(23)$ converged with accuracy $\varepsilon=10^{-5}$ to the solution of the problem for the function $u(x)$ in 9 iterations.

Fig. 1 shows the graphs of the upper $w^{(k)}(x)$ (dotted line) and lower $v^{(k)}(x)$ approximations (dashed line), $k=0,1, \ldots, 9$, Fig. 2 shows a graph of the approximate solution $u^{(9)}(x)$, and Fig. 3 shows a graph of the approximate solution $T^{(9)}(x)$. Tables 1 and 2 show the values of the approximate solutions $u^{(9)}(x)$ and $T^{(9)}(x)$ on the grid with step 0,1, respectively. 
Fig. 1 clearly demonstrates the two-sided character of the convergence of the constructed iterative sequences $\left\{v^{(k)}(x)\right\}$ and $\left\{w^{(k)}(x)\right\}$ in accordance with the chain of inequalities (24): at each $k$ th iteration, the unknown exact solution $u^{*}(x)$ of problem (9)-(11) is above the approximation $v^{(k)}(x)$ and below the approximation $w^{(k)}(x)$

Tab le 1 . The value of the approximate solution $u^{(9)}(x)$

\begin{tabular}{|c|c|c|c|c|c|c|}
\hline$x$ & $\mathbf{0 , 0}$ & 0,1 & 0,2 & 0,3 & 0,4 & 0,5 \\
\hline$u^{(9)}(x)$ & 0,000000 & 0,017262 & 0,031830 & 0,042761 & 0,049515 & 0,051798 \\
\hline$x$ & 0,6 & 0,7 & 0,8 & 0,9 & 1,0 & \\
\hline$u^{(9)}(x)$ & 0,049515 & 0,042761 & 0,031830 & 0,017262 & 0,000000 & \\
\hline
\end{tabular}

Table 2. The value of the approximate solution $T^{(9)}(x)$

\begin{tabular}{|c|c|c|c|c|c|c|}
\hline$x$ & $\mathbf{0 , 0}$ & $\mathbf{0 , 1}$ & $\mathbf{0 , 2}$ & $\mathbf{0 , 3}$ & $\mathbf{0 , 4}$ & $\mathbf{0 , 5}$ \\
\hline$T^{(9)}(x)$ & 0,000000 & 0,448497 & 0,534180 & 0,581191 & 0,606059 & 0,613914 \\
\hline$x$ & $\mathbf{0 , 6}$ & $\mathbf{0 , 7}$ & $\mathbf{0 , 8}$ & $\mathbf{0 , 9}$ & $\mathbf{1 , 0}$ & \\
\cline { 1 - 5 }$T^{(9)}(x)$ & 0,606059 & 0,581191 & 0,534180 & 0,448497 & 0,000000 & \\
\cline { 1 - 4 } & &
\end{tabular}

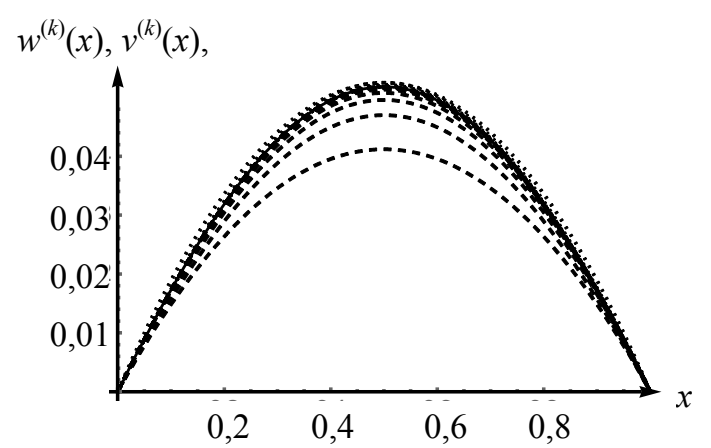

Fig. 1. Graphs of $v^{(k)}(x)$ and $w^{(k)}(x), k=0,1,2,3,4,5,6,7,8,9$

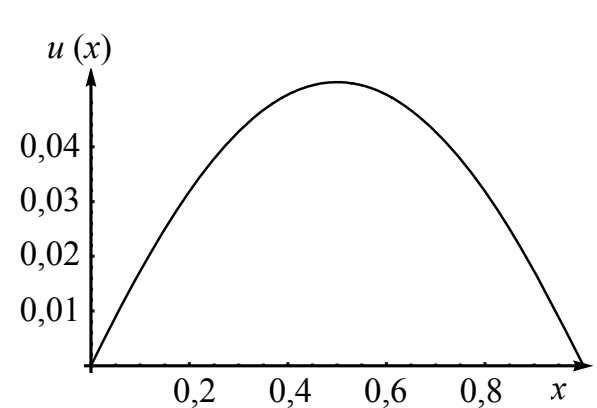

Fig. 2. Graph of $u^{(9)}(x)$

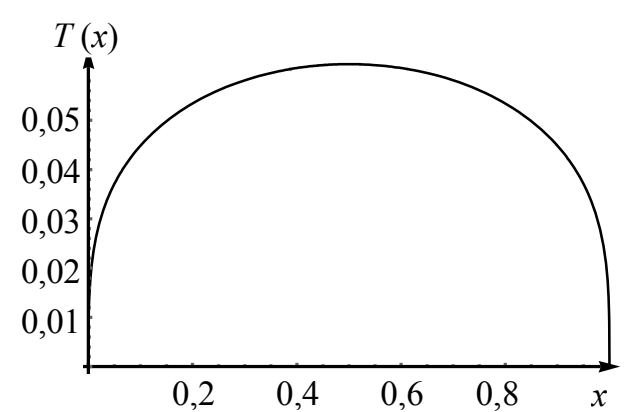

Fig. 3. Graph of $T^{(9)}(x)$

The dependence of the norm of solutions $u(x)$ and $T(x)$ at $\sigma=2,5$ depending on the value of the parameter $\gamma$ was also investigated numerically. Iterations were carried out until four significant digits were clarified in the norm of the approximate solution $u^{(k)}$. The corresponding graphs of the 
dependence of the norms on the parameter $\gamma$ are shown in Fig. 4 and 5. As we can see, with increasing parameter $\gamma$, the norms of solutions $u(x)$ and $T(x)$ go to zero.

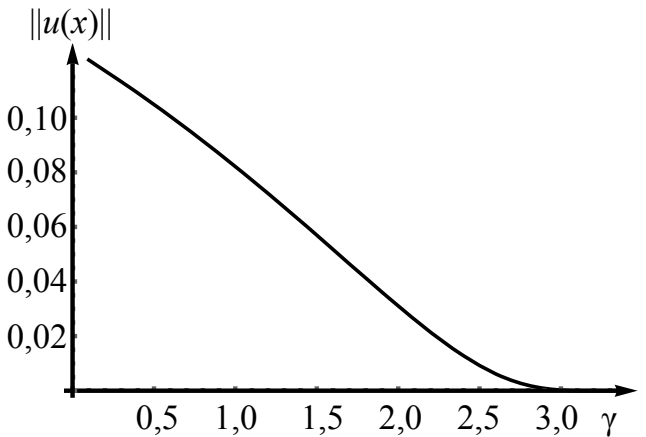

Fig. 4. Graph of the dependence of the norm of solution $u(x)$ on the parameter $\gamma$

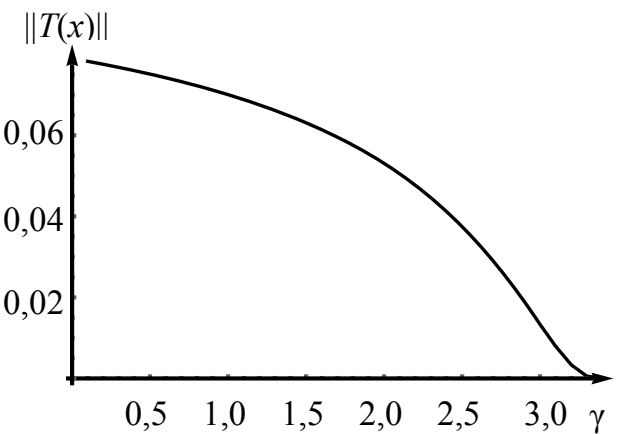

Fig. 5. Graph of the dependence of the norm of solution $T(x)$ on the parameter $\gamma$

The rate of convergence of the iterative process was estimated by the value $\frac{\varepsilon_{k+1}}{\varepsilon_{k}}$, where $\varepsilon_{k}=\max _{x \in[0,1]}\left(w^{(k)}(x)-v^{(k)}(x)\right), k=1,2, \ldots$. It is established that the process coincides with the speed of geometric progression. Estimation of the denominator $q$ of this progression depending on $\gamma$ is given in Table. 3. As one can see, with increasing $\gamma$, the value of $q$ approaches unity, which indicates deceleration in the convergence of iterations.

Table 3. The value of the estimate of the rate of convergence $q$ for different values of $\gamma$

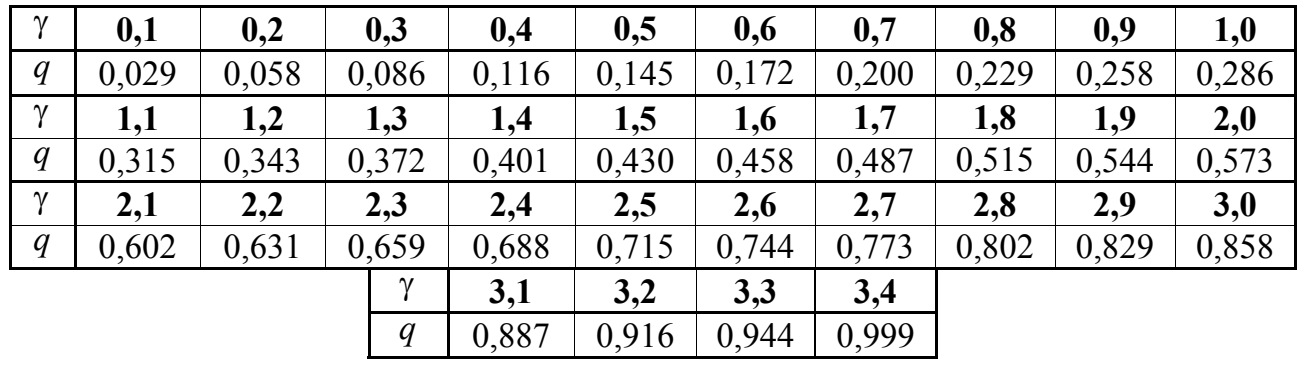

\section{CONCLUSIONS}

The problem of construction of two-sided approximations to the positive solution of the first boundary value problem for a nonlinear one-dimensional equation of thermal conductivity is solved in the work.

The scientific novelty of the results obtained lies in the fact that the method of two-sided approximations for solving nonlinear operator equations with an isotonic operator was further developed in terms of its application to boundary value problems for the nonlinear one-dimensional heat equation. The developed method has a few advantages, such as a convenient a posteriori estimation of the error of the approximate solution and a simple computational algorithm. This distinguishes it from other numerical methods for solving boundary value problems for nonlinear ordinary differential equations of the second order and makes it attractive for application in engineering practice. 
The practical significance of the results obtained lies in the fact that the proposed method has shown itself well in solving test problems, allows fast software implementation, which will allow carrying out highly invariant computational experiments when solving practical problems of mathematical modeling of nonlinear processes.

The limited use of the method can be associated with the conditions imposed on the behavior of nonlinearities included in the equations of the boundary value problem.

Prospects for further research are the extension of the method of two-sided approximations developed in this work to boundary value problems for ordinary differential equations with other types of nonlinearities, in particular, exponential ones, as well as to initial boundary value problems for quasilinear parabolic equations, using semi-discrete methods (for example, the Rothe line method).

\section{REFERENCES}

1. C.V. Pao, Nonlinear parabolic and elliptic equations. New York: Plenum Press, 1992. Available: https://doi.org/10.1007/978-1-4615-3034-3

2. A.A. Samarskii and A.P. Mikhailov, Principles of Mathematical Modelling: Ideas, Methods, Examples. London: CRC Press, 2001. Available: https://doi.org/10.1201/ 9781482288131

3. D.A. Frank-Kamenetskii, Diffusion and Heat Exchange in Chemical Kinetics. Princeton: Princeton University Press, 1955. Available: https://doi.org/10.1515/9781400877195

4. A.A. Samarskii, V.A. Galaktionov, S.P. Kurdyumov, and A.P. Mikhailov, Blow-Up in Quasilinear Parabolic Equations. Berlin, New York: Walter de Gruyte, 1995. Available: https://doi.org/10.1515/9783110889864

5. A.A. Samarskii, The Theory of Difference Schemes. New York: CRC Press, 2001. Available: https://doi.org/10.1201/9780203908518

6. N.A. Kudryashov, A.V. Khlunov, and M.A. Chmykhov, "Thermal regimes of high burnup nuclear fuel rod", Communications in Nonlinear Science and Numerical Simulation, vol. 15, no. 5, pp. 1240-1252, 2010. Available: https://doi.org/10.1016/j. cnsns.2009.05.063

7. G. Chen, J. Zhou, and W.-M. Ni, "Algorithms and visualization for solutions of nonlinear elliptic equations", International Journal of Bifurcation and Chaos in Applied Sciences and Engineering, vol. 10, no. 7, pp. 1565-1612, 2000. Available: https://doi.org/10.1142/ S0218127400001006

8. M. Kumar and G. Mishra, "An introduction to numerical methods for the solutions of partial differential equations", Applied Mathematics, vol. 2, no. 11, pp. 1327-1338, 2011. Available: https://doi.org/10.4236/am.2011.211186

9. M.V. Sidorov, "Method of two-sided approximations of the solution of the first boundary value problem for nonlinear ordinary differential equations based on the Green's function use", Radio Electronics, Computer Science, Control, no. 1 (48), pp. 57-66, 2019. Available: https://doi.org/10.15588/1607-3274-2019-1-6

10. M.V. Sidorov, "Green-Rvachev's quasi-function method for constructing two-sided approximations to positive solution of nonlinear boundary value problems", Carpathian Mathematical Publications, vol. 10, no. 2, pp. 360-375, 2018. Available: https://doi.org/10.15330/cmp.10.2.360-375

11. L.V. Kantorovich and G.P. Akilov, Functional Analysis. New York: Pergamon, 1982. Available: https://doi.org/10.1016/C2013-0-03044-7

12. M.A. Krasnosel'skii, Positive Solutions of Operator Equations. Groningen: Noordhoff, 1964. Available: https://www.worldcat.org/title/positive-solutions-of-operatorequations/oclc/1316344

13. H. Amann, "Fixed point equations and nonlinear eigenvalue problems in ordered Banach spaces", SIAM Review, vol. 18, no. 4, pp. 620-709, 1976. Available: https://doi.org/10.1137/1018114

14. V.I. Opojtsev, "A generalization of the theory of monotone and concave operators", Transactions of the Moscow Mathematical Society, vol. 36, pp. 243-279, 1979. Available: https://zbmath.org/?q=an:0451.47075 
15. B.A. Shuvar and M.I. Kopach, "Two-sided operator inequalities with nonmonotone operators", Differential Equations, vol. 42, pp. 586-590, 2006. Available: https://doi.org/10.1134/S001226610604015X

16. A.I. Kolosov, "A boundary value problem on a nonfixed interval", Siberian Mathematical Journal, vol. 17, no. 6, pp. 944-948, 1976. Available: https://doi.org/10. 1007/ BF00968020

Received 27.09.2021

\section{INFORMATION ON THE ARTICLE}

Nadiia V. Gybkina, ORCID: 0000-0002-2564-6903, Kharkiv National University of Radio Electronics, Ukraine, e-mail: nadiia.gybkina@nure.ua

Maxim V. Sidorov, ORCID: 0000-0001-8022-866X, Kharkiv National University of Radio Electronics, Ukraine, e-mail: maxim.sidorov@nure.ua

Kostiantyn V. Vasylyshyn, ORCID: 0000-0002-6123-8683, Kharkiv National University of Radio Electronics, Ukraine, e-mail: kostiantyn.vasylyshyn@nure.ua

ЗАСТОСУВАННЯ МЕТОДУ ДВОБІЧНИХ НАБЛИЖЕНЬ ДО РОЗВ'ЯЗАННЯ ПЕРШОЇ КРАЙОВОЇ ЗАДАЧІ ДЛЯ ОДНОВИМІРНОГО НЕЛІНІЙНОГО РІВНЯННЯ ТЕПЛОПРОВІДНОСТІ / Н.В. Гибкіна, М.В. Сидоров, К.В. Василишин

Анотація. Розглянуто першу крайову задачу для одновимірного нелінійного рівняння теплопровідності, де коефіцієнт теплопровідності та функція потужності теплових джерел степенево залежать від температури. Для числового аналізу цієї задачі запропоновано використати метод двобічних наближень на основі методу функцій Гріна. Після заміни невідомої функції крайова задача зведена до інтегрального рівняння Гаммерштейна, яке розглянуто як нелінійне операторне рівняння у напівупорядкованому банаховому просторі. Отримано умови існування єдиного додатного розв'язку задачі та умови двобічної збіжності до нього послідовних наближень. Розроблений метод програмно реалізовано та досліджено під час розв'язання тестових задач. Результати обчислювального експерименту проілюстровано графічною та табличною інформаціями. Проведені експерименти підтвердили працездатність та ефективність розробленого методу і дозволяють рекомендувати його для використання на практиці для розв'язання задач системного аналізу та математичного моделювання нелінійних процесів.

Ключові слова: нелінійна теплопровідність, додатний розв'язок, функція Гріна, двобічний ітераційний метод, рівняння з ізотонним оператором.

\section{ПРИМЕНЕНИЕ МЕТОДА ДВУСТОРОННИХ ПРИБЛИЖЕНИЙ К РЕШЕНИЮ ПЕРВОЙ КРАЕВОЙ ЗАДАЧИ ДЛЯ ОДНОМЕРНОГО НЕЛИНЕЙНОГО УРАВ- НЕНИЯ ТЕПЛОПРОВОДНОСТИ / Н.В. Гибкина, М.В. Сидоров, К.В. Василишин}

Аннотация. Рассмотрена первая краевая задача для одномерного нелинейного уравнения теплопроводности, в которой коэффициент теплопроводности и функция мощности тепловых источников являются степенными функциями температуры. Для численного анализа этой задачи предложено использовать метод двусторонних приближений на основе метода функций Грина. После замены искомой функции краевая задача сведена к интегральному уравнению Гаммерштейна, рассматриваемому как нелинейное операторное уравнение в полуупорядоченном банаховом пространстве. Получены условия существования единственного положительного решения задачи условия двусторонней сходимости к нему последовательных приближений. Разработанный метод программно реализован и исследован при решении тестовых задач. Результаты вычислительного эксперимента проиллюстрированы графической и табличной информациями. Проведенные эксперименты подтвердили работоспособность и эффективность разработанного метода, что позволяет рекомендовать его для использования на практике при решении задач системного анализа и математического моделирования нелинейных процессов.

Ключевые слова: нелинейная теплопроводность, положительное решение, функция Грина, двусторонний итерационный метод, уравнение с изотонным оператором. 